Preschoolers do not generalize dominance roles from one situation to another

\author{
Narges Afshordi \\ Harvard University, University of Minnesota \\ This version of the paper has been submitted for peer review. \\ Comments and questions are encouraged and can be sent to afshordi@umn.edu.
}

* Corresponding author: Narges Afshordi, Institute of Child Development, University of Minnesota. 51 E River Parkway, Minneapolis, MN 55455. Electronic mail may be sent to afshordi@umn.edu.

Acknowledgments: I am deeply grateful to Susan Carey for her input and support on this work, and to Melissa Koenig for supporting the project in its later stages. I wish to thank Esme Trahair, Jessica Pu, Mehrnaz Mirhosseini, and Sydney Cheung for their assistance in recruitment and data collection. I am grateful to Charlotte Anne Dore for her contribution to the puppet animations and to the lab mates who lent their voice to the puppets. Last but not least, my sincere thanks to the children and families as well as adult participants who took part in the studies. 


\begin{abstract}
Recognizing social rank as a third-party observer is an important social skill. With regard to dominance-the coercive form of social rank-infants expect the winner of a zero-sum conflict over one type of resource to win again when competing with the same agent over a different type of resource (Mascaro \& Csibra, 2012). However, it is unclear whether preschoolers also expect dominant-subordinate roles to generalize across situations. The current study tested this question with preschoolers ( $3-5$ years, $n=280,140$ female, USA, $80 \%$ White) and adults ( $n=200,99$ female, USA, 75\% White). Preschoolers and adults recognized the dominant puppet in two resource conflict situations (a toy to play with, a bench to sit on) in which one puppet won by force and the other lost (Exp. 1). Preschoolers did not expect the puppet who had been dominant in one situation (e.g. toy) to win again in a new situation (e.g. bench) (Exp. 2a and 2b). Adults, like infants, thought the dominant puppet would win again (Exp. 2b). When the concepts of dominance and fairness were primed (Exp. 3), preschoolers' inferences about the winner diverged: Children who had been primed with dominance thought the subordinate would win, while those who had been primed with fairness responded at chance level. This finding, together with converging support from children's justifications, suggests that preschoolers are particularly sensitive to the unfairness of dominance interactions, and indicates that this consideration affects their inferences about the stability of dominance.
\end{abstract}

Keywords: dominance, social inference, social rank 


\section{Preschoolers do not generalize dominance roles from one situation to another}

Social rank—-the relative difference between individuals along a continuum of influence and power-is a pervasive and evolutionarily deep feature of human communities (Fiske, 1992; Sidanius \& Pratto, 2001; Van Vugt \& Tybur, 2015). Infants as young as one year can be ranked based on their behavior during conflict with peers (Russon \& Waite, 1991), and the same holds true for preschool-aged children (Charlesworth \& La Freniere, 1983). Such hierarchical organization, as dominance in particular, decreases the long-term expression of aggression and its costs, as those of lower rank adopt a strategy of yielding rather than engaging in conflicts that they are likely to lose (Bernstein, 1981). In preschool classrooms, for example, aggression and bouts of conflict decrease over the course of a year (Pellegrini et al., 2007).

Given the ubiquity and utility of hierarchies, recognizing signs of rank is beneficial, both as a participant in hierarchical relationships and also as a third-party observer of others' relationships. Indeed, infants' and young children's competition for social rank is complemented by their recognition of it based on various cues and behaviors. In the context of simple zero-sum games where only one of two agents can win, infants expect physically larger agents (Thomsen et al., 2011) and members of numerically larger groups (Pun et al., 2016) to prevail. Infants also expect dominant individuals to receive larger allocations of resources (Enright et al., 2017), for transitivity to hold along a chain of dominance rankings (Gazes et al., 2017), and for dominance hierarchies to be linear rather than circular in structure (Mascaro \& Csibra, 2014). By the preschool period, children infer higher social rank from a multitude of cues including body size, physical might, age difference, decision-making power, unequal resources, resource control, goal achievement, seeking permission, setting norms, observed imitation, non-verbal cues such as posture, and facial features (Terrizzi et al., 2019; Charafeddine et al., 2015; Gulgoz \& Gelman, 2016; Over \& Carpenter, 2015; Brey \& Shutts, 2015; Cogsdill et al., 2014). Furthermore, young children's reasoning about social rank indicates their burgeoning grasp of big picture societal level inequalities. Children infer possession of more resources based on an 
existing rank difference (Charafeddine et al., 2015), and associate higher rank with male individuals (Charafeddine et al., 2020; Mandalaywala et al., 2020). Thus, infants and preschoolers recognize many aspects of social rank.

Most of the developmental literature reviewed above has construed social rank as social dominance. However, dominance is one of two main processes that lead to higher rank amongst humans (Henrich \& Gil-White, 2001; Hawley, 1999). While dominance is a coercive form of rank based on force or the threat of force, humans also display prestige, a non-coercive form based on merit and respect in the eyes of others. Both strategies can eventuate in higher rank for adults (Cheng \& Tracy, 2014), but it is generally prestigious individuals who are admired, sought out for counsel, and learned from (Henrich \& Gil-White, 2001). In children, coercive strategies generally pay off in the preschool period, but cease to be effective in peer settings by middle childhood (Hawley, 2002; 2003). As third-party observers, infants expect agents to heed the directions of an absent leader if she is respected and prestigious, but not if she is dominant and coercive (Margoni et al., 2018). Toddlers demonstrate a preference for a winner of a zero-sum game who won because the other agent willingly moved out of the way, but hold no such preference if the winner used force to achieve its goal (Thomas et al., 2018). Preschoolers identify prestige from bystander attention, a cue that signals interest from others (Chudek et al., 2012; Enright et al., 2020). Further, children as young as five years expect a subordinate character to like and approach a prestigious individual, but to fear a dominant one (Kajanus et al., 2020). Five-year-olds also expect a chosen leader to contribute more than average to a shared cause but receive an equal share (Stavans \& Diesendruck, 2020). Thus, infants and young children are somewhat competent in telling apart high-ranking individuals who dominate from those who lead.

Despite these impressive findings about young children's inferential abilities with regard to social rank, fundamental aspects of their conceptual understanding require further investigation. Within coercive dominance specifically, it is unclear whether dominant- 
subordinate roles are conceptualized as stable across different situations or as subject to change. If dominance is a stable relationship between two individuals-at least in the absence of any event that could upset the existing balance-the high-ranking party within a pair should remain high-ranking regardless of the particulars of the situation. In other words, the physical force or threat of force that lies at the root of the dominant individual's higher rank should not change from one conflict situation to the next. Exploring this very issue, Mascaro and Csibra (2012) tested infants in a looking-time paradigm. They showed infants animations of two agents interested in collecting the same object. One agent succeeded, hence being the dominant party, while the other failed, hence being the subordinate. By 12-month-olds, infants expected the dominant agent from a previous conflict to be dominant in a new situation, even though the object under dispute had changed. More strikingly, by 15-month-olds infants expected an agent who had been dominant in holding on to a small enclosure to be dominant when collecting objects. In short, infants expected a dominant party to stay dominant in a new situation.

The first and main goal of this paper is to test whether preschoolers make the same type of generalization for dominance roles across situations. This question is important to answer because it would pave the way for answering other key questions about children's discrimination of dominance from prestige. For instance, do preschoolers think that the individual who physically coerces others in a resource conflict (i.e. dominant) is also the one setting trends amongst peers (i.e. prestigious)? The first step towards answering this type of bigger question regarding the far generalization of social rank from dominance to prestige is to test whether there is near generalization across dominance conflicts. Going from one type of resource conflict to the next, do preschoolers think the party who won the first time around will win again? On the one hand, Mascaro and Csibra's (2012) findings could be taken as reason to suggest that preschoolers, like infants, would also generalize dominance roles across situations. On the other hand, infancy findings do not always match results from older children. For instance, divergent results between infants and older children have been reported for false belief 
understanding (e.g. Onishi \& Baillargeon, 2005; Wellman et al., 2001), reasoning about solidity constraints (Spelke et al., 1992; Hood et al., 2000), and inferring affiliation from observed imitation (Over \& Carpenter, 2015, Powell \& Spelke, 2018; Afshordi \& Carey, under review). In sum, it is possible that preschoolers, like infants, would generalize dominance roles across different types of conflicts. Alternatively, it is possible that preschoolers would be unsystematic in their inferences as a group. Finally, it is even possible that preschoolers would infer that dominance roles would be reversed across different situations, for instance because they often encounter turn-taking in peer settings. To test this, I conducted several experiments. In Experiment 1, I showed preschoolers and adults puppet animations and tested whether they recognize the dominant party in two different conflict situations. In Experiments $2 a, 2 b$, and 3, I used these animations to test whether preschoolers and adults infer the dominant party in one situation to be dominant in another. In order to gain more insight into children's reasoning, I also asked participants to explain why the agent they chose as the winner has won.

The second goal of this paper is to test whether preschoolers have a preference between a dominant individual and a subordinate one. Previous work has found that infants prefer a subordinate to a dominant agent (Thomas \& Sarnecka, 2019), while toddlers prefer a dominant individual so long as the agent did not win by force (Thomas et al., 2018). Evidence from preschoolers is also mixed. Although a lack of preference for either party has been found in several cases, reports of a preference for the dominant and the subordinate also exist (Charafeddine et al., 2018; Charafeddine et al., 2016, Enright et al., 2020, Castelain et al., 2015). What is clear from this divergence is that preschool-aged children do not seem to have a strong preference between high- vs. low-ranking parties, especially in the case of dominance. Rather, their preference is highly malleable and most likely subject to the specifics of how rank was established. Given this confusion, adding data to the mix can be helpful as they provide future meta-analyses with the opportunity to reveal what variables drive preschoolers' preferences one way or another. Thus, in all the experiments, I asked preschoolers whom they 
preferred. In order to get more purchase on the motivations behind their choice, I went a step further from previous work and asked children to also justify their preference.

\section{Experiment 1}

The goal of this experiment was to test whether children and adults recognized the dominance relationship between puppet characters in two separate conflict situations. This test ensured participants viewed the animations as intended before testing the main question of the study in subsequent experiments. Each of the two situations shown here involved two characters physically struggling over a resource that only one ended up with: a toy to play with in one case, and a bench to sit on in the other.

Previous studies have used the terms "in charge" or "boss" to test children's identification of the dominant individual (e.g. Brey \& Shutts, 2015; Gulgoz \& Gelman, 2016). However, I chose to ask "Which one is stronger?" instead. Here, making an inference about who is stronger is equivalent to identifying who is dominant because the struggle between the two puppets is clearly physical, necessitating that the winner of the zero-sum game be the stronger character. In contrast, terms like "in charge" could signal that a stable hierarchical relationship persists beyond the current situation. For instance, Brey and Shutts (2015) offered children the following definition for "in charge" before posing any questions, "the person who is in charge is the one who makes up all the rules and tells others what to do, like the boss." Here, offering such a definition may have suggested that the person who won the conflict did so because they were the boss, not just now, but possibly also in the past and the future. This could interfere with another question that was posed in this experiment, which asked who would win the same resource again if a new bout of conflict broke out.

If children recognize that the dominant individual in a pair is the one who secures the resource, they will name that puppet as the one who is 'stronger'. They will not do so, however, if the animations are confusing to understand or open to different interpretations in terms of the 
outcome. Additionally, this experiment began to test whether preschoolers have a preference between the dominant and subordinate characters.

\section{Method}

Participants. A total of 72 preschoolers ${ }^{1}$ (3-year-olds: $n=24, M=41.9$ months, 14 female; 4-year-olds: $\mathrm{n}=24, M=51.8$ months, 10 female; 5 -year-olds: $\mathrm{n}=24, M=67.6$ months, 13 female) participated. Two additional children were excluded for failing to complete the task (1) and experimenter error (1). Children were recruited from a database of families in the area interested in developmental research. The database is mostly middle-class and White (79\% European American, 15\% Asian American, 6\% African American). Additionally, 128 adults ( $M=34.8$ years, 66 female, $2 \%$ American Indian or Alaska Native, $11 \%$ Asian, $5 \%$ Black or African-American, $75 \%$ White, $5 \%$ mixed, and $2 \%$ other) participated in the experiment online. They were recruited on Amazon mTurk and took part in the study on the Qualtrics platform.

Materials. Videos of two pairs of puppets, one male and one female, were prepared for two different situations (Toy and Bench). See Figure 1 for a picture of the puppets. In each situation, the puppets competed over a resource at the center of the screen (a cube with a ball inside in the Toy situation, and a bench in the Bench situation). A professional puppeteer handled the puppets, and videos were filmed against a chroma key panel to remove the background. Puppets were voiced by different adults whose utterances were filtered to sound child-like and cartoonish. For children, stimuli were displayed on a 13-inch laptop. To minimize distraction, the keyboard was covered and a wireless mouse, held out of the child's view, was used. Any spoken narration or questions provided by the experimenter were presented in written form for adults.

\footnotetext{
${ }^{1}$ The main question of the paper is whether preschoolers generalize dominance across situations. Given that this was a single-item test, each child provided only one binary response. A power analysis for a binomial test with a small to medium effect size (Cohen's $h$ ) of $0.35, a=0.05$, and power (1- $\beta$ ) of 0.8 found the sample size of 66 . This is increased slightly to samples of 72 in the preschooler samples of Experiments 1, 2a, and 2b. Adults were easier to recruit than children, and in order to get a sense of how prevalent their intuitions were, a larger sample of 128 were recruited in Experiment 1, but their number matched preschoolers in Experiment 2b.
} 


\section{Figure 1}

\section{Puppet pairs}
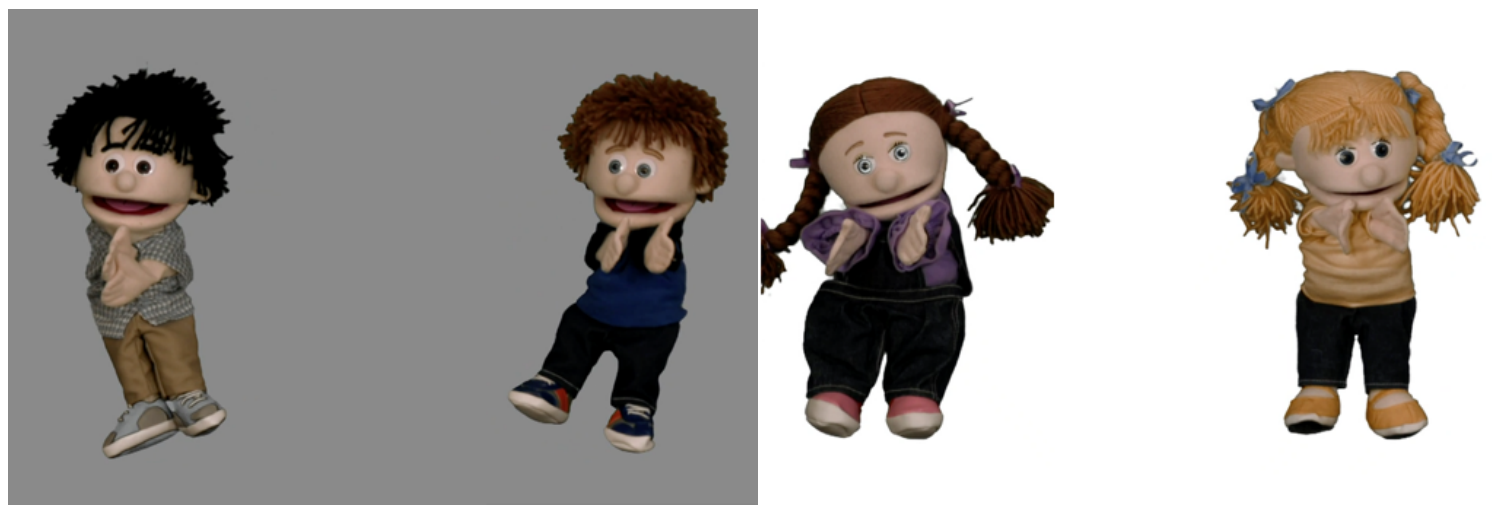

Note. Picture of the male puppet pair (left) and female puppet pair (right) used in animations

Procedure. Each participant completed two blocks (Toy and Bench). Block order and gender of the puppets for each block (i.e. male puppets in Toy block or Bench block) were counterbalanced across participants. The structure of each block was as follows:

Introduction. A picture of the two puppets appeared and the experimenter introduced them. Puppets' names reflected their appearance so that children would easily distinguish and remember them. For instance, "This is BrownPants, and this is BlackPants. BrownPants is wearing brown pants and BlackPants is wearing black pants." The female puppets were called YellowShirt and PurpleShirt.

Entrance. Each puppet, in the absence of the other, entered from one side of the screen and moved towards the center. The experimenter provided brief narrations, e.g. "Here is BrownPants." The puppet stopped before reaching the resource and said, "Wow!" The puppet then continued to the center, where he or she either picked up the toy and played with it by moving it around (Toy block), or sat on the bench, dancing from side to side (Bench block). Children watched each character enter three times. These entrances demonstrated that both puppets were interested in the resource. Next, participants saw a picture of the puppets 
standing equidistant from the resource. The experimenter tested memory of puppet names, and corrected wrong responses.

Conflict. The puppets simultaneously moved towards the desired resource, stopping midway to express interest, e.g., "Nice bench!" They then moved towards the object and struggled over it. In the Toy situation, they each grabbed hold of one side of the toy and pulled it towards themselves. The toy went back and forth a number of times before being yanked away by one puppet. The puppets then separated and the winner played with the toy saying, "Yay! Yay!" The loser bent their head, demonstrating disappointment. In the Bench situation, the puppets sat on the bench simultaneously and each tried to push the other off. After going back and forth a few times, one managed to win. The winner danced on the bench while seated and said, "Yay! Yay!" The loser remained bent over, signaling disappointment. The conflict video was shown three times. At the start of each viewing, the experimenter made a comment that made it seem like this was a new instance of the conflict (e.g. "Let's see what happens now.").

Test. Showing a picture of the puppet pair (see Figure 1), the experimenter asked the following test questions:

1. Outcome. This question checked attention to the events, "Who got to take the toy?" (Toy block) or "Who got to sit on the bench?" (Bench block).

2. Strength. "Who is stronger?"

3. Prediction-Same situation. Participants watched a new video of the same conflict situation, showing the characters approaching and struggling over the same resource as before. This video stopped during the struggle, and participants had to predict the winner, e.g. "Oh! The video got stuck. Who's going to take the toy?" Although this conflict was very similar to the one in the Conflict phase, it was in fact a different video and the puppets said slightly different things as they approached the resource, e.g. "Cool toy!" instead of "Nice toy!"

4. Preference. The picture of the two puppets appeared again, and the experimenter asked, "Which one do you like best?" 
5. Preference Justification. "Why do you like [chosen puppet] best?"

6. Prediction Justification. "Why do you think [chosen puppet] took the toy/sat on the bench?"

For children, Preference Justification and Prediction Justification questions were only asked on the second block, whichever it happened to be. Adults gave justifications for both blocks. Each child received the Outcome question before the Strength question in one block and vice versa in the other block.

Coding. The following coding scheme was used for all experiments: Remembering the names of both puppets was coded as correct for the name memory question. For all other questions (Outcome, Strength, Prediction-Same situation, Preference, etc.), a choice for the dominant puppet was coded as 1 and a choice for the subordinate was coded as 0 .

\section{Results}

Data from this experiment as well as subsequent experiments can be viewed at https://osf.io/tcuxn/?view_only=8dbd67d74be74970b86ddfa1679f0b80. Analyses were conducted in R (R core team, 2017). All comparisons against chance for questions in which a participant provided more than one response were conducted with a mixed-effects binary logistic regression that included only the intercept as a fixed effect and participant as a random effect. A mixed-effects binary logistic regression including age group (child, adult), puppet pair (girl puppets, boy puppets), and situation type (Toy, Bench) as fixed effects and participant as a random effect was run on pooled data from children and adults.

Memory questions. Children correctly remembered the identity of each puppet $(92.4 \%$ correct, $\mathrm{OR}=12.1, p<.0001)$. There was an effect of age (in months; $\mathrm{OR}=2.7,95 \% \mathrm{Cl}=1.05$, $7 ; p=.038)$, but no effect of puppet pair, and no interaction between the two. Follow-up analyses revealed that despite the age effect, 3-, 4-, and 5-year-olds were all better than chance at remembering puppet names (all $p<.05$ ). Almost all adults remembered the identity of the puppets in both situations $(98.8 \%$ correct, OR $=84.33, p<.0001)$. 
Test questions. Results are separated by test questions below (see Figure 2).

\section{Figure 2}

\section{Experiment 1 responses}

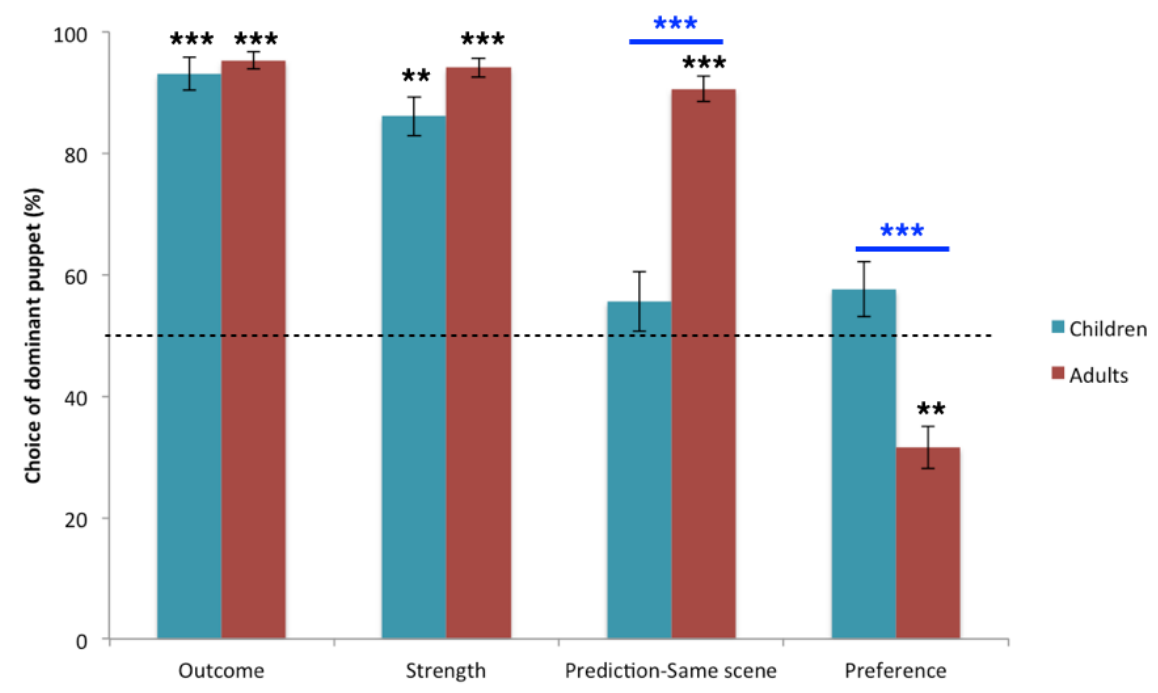

Note. Comparisons against chance (black) and across ages (blue) are noted $\left({ }^{* *} p<0.01,{ }^{* *} p<\right.$ 0.001). Error bars reflect standard error of the mean. Dotted line shows chance level.

Outcome. Almost all children's responses were correct $(93.1 \%$ correct, $\mathrm{OR}=17,500, p$ $<.0001)$, as were those of adults $(95.3 \%, \mathrm{OR}=3831.45, p<.0001)$. For children, there was no effect of age $(p=.3)$, meaning that performance was high across the board. Children's responses were not statistically different from adults $(p=.8)$, nor was there an effect of puppet gender or situation (Toy, Bench).

Strength. Children chose the dominant puppet as the stronger one on $86.1 \%$ of trials $(\mathrm{OR}=14.8, p=.002)$, and adults did so $94.1 \%$ of the time $(\mathrm{OR}=3759.3, p<.0001)$. Within the child sample, there was significant improvement with age $(\mathrm{OR}=1.13,95 \% \mathrm{Cl}=1.7,1007.6, p=$ .02). Follow-up tests found that all preschooler age groups answered the Strength question correctly significantly more often than chance, even three-year-olds (75\% correct, $p<.001)$. 
Children's responses were statistically comparable to those of adults $(p=.27)$, and there was no effect of puppet gender or situation type.

Prediction-Same situation and Prediction Justification. Children chose the dominant puppet $55.6 \%$ of the time in response to the prediction question, which was not significantly different from chance $(p=.23)$. This indicates that children did not think the dominant puppet would win the resource if a conflict over it broke out again. There was no effect of age or situation type in children's performance, but there was a significant effect of gender $(\mathrm{OR}=.39,95 \% \mathrm{Cl}=0.15,0.92, p=.04)$, showing that girls' responses were lower than boys'. Adults, in contrast, chose the dominant puppet as the winner at a very high rate $(90.2 \%, \mathrm{OR}=$ 4109.3, $p<.0001)$. When comparing children and adults, there was no effect of puppet pair or situation, but there was a main effect of age group $(\mathrm{OR}=.01 ; 95 \% \mathrm{Cl}=0,0.07 ; p<.0001)$ such that children were less likely than adults to choose the dominant puppet as the winner.

As mentioned above, children gave a single prediction justification for their second block, while adults provided one in each block. Prediction Justification responses were coded into the following categories:

1. Dominance: mentioning use of force, strength, the past win, etc. For instance, "Because she's stronger.", "Because he pushed the other one off.", "She won the other three times."

2. Fairness: mentioning fairness, sharing, taking turns, the past loss. For instance, "Because he didn't take it last time."

3. Other: providing a reason unrelated to dominance or fairness, not responding, shrugging. For instance, "I don’t know."

The author read all responses, generated the set of categories and coded responses in a first pass, then communicated the categorization system to two coders who coded responses independently of each other. The author made a final decision about the category for each response after considering the coders' choices. Figure 3 shows the rates of responses within 
each category separated by whether the participants predicted the dominant or subordinate puppet to be the winner. If the question was not asked of the child (e.g. experimenter error), the participant was excluded from justification analyses.

\section{Figure 3}

Prediction justifications from prescholers and adults in Experiment 1

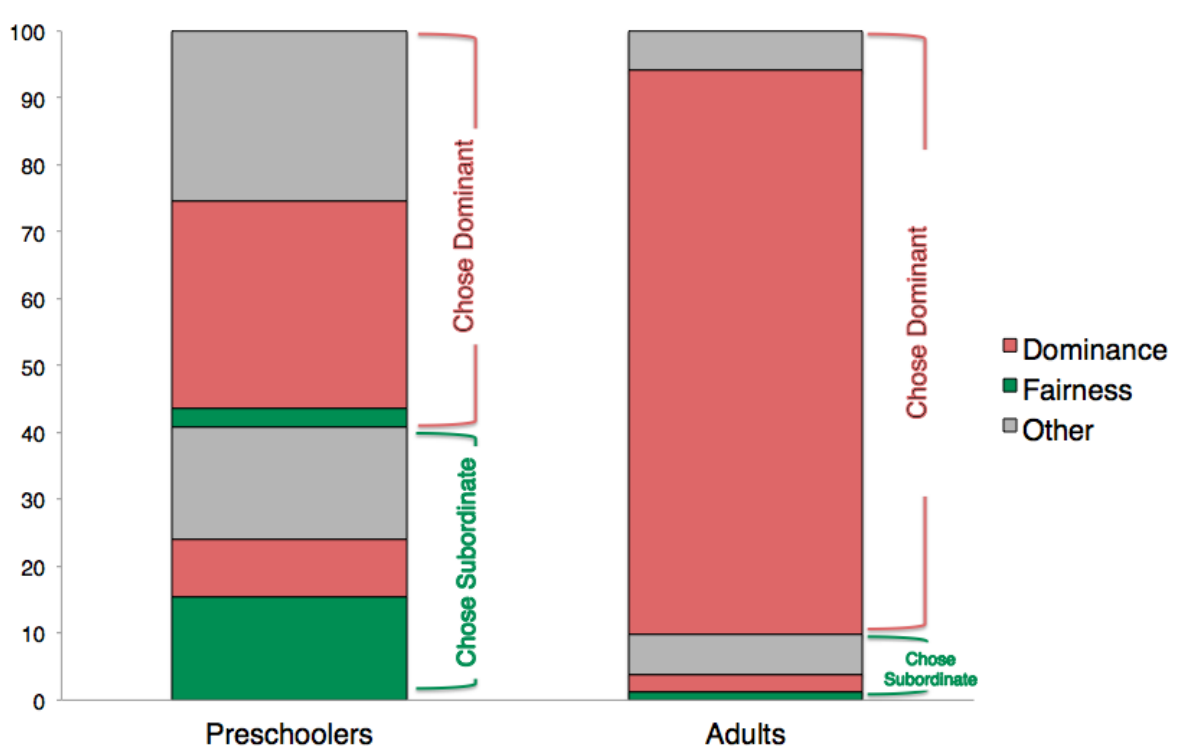

Note. Justifications are broken down by whether the respondents chose the subordinate or dominant puppet as the winner of the conflict, and are color coded by category.

Within child respondents, the pattern of justifications was significantly different across children who picked the dominant puppet (52\% Dominance justifications, $5 \%$ Fairness justifications, $43 \%$ Other) and those who picked the subordinate (21\% Dominance justifications, $38 \%$ Fairness justifications, $41 \%$ Other $)$ as the winner $\left(X^{2}(2, N=71)=14.63, p=.0007\right.$, Cramer's $V=0.46)$. Laying aside responses in the Other category, Dominance and Fairness justifications were distributed differently across children who chose the dominance and subordinate puppets $\left(X^{2}(1, N=41)=14.6, p=.0001\right.$, Cramer's $\left.V=0.6\right)$. What these tests 
indicate is that children who picked the dominant puppet gave more Dominance explanations, while children who picked the subordinate offered more Fairness justifications.

The pattern of justifications was different for adults compared to children. The majority of adults chose the dominant puppet $(90.2 \%)$ and the majority of those who did so gave Dominance justifications (94\%). Fairness responses were almost non-existent (1\% of all responses). Thus, the question of who would win in the new situation was straightforward to adults: the dominant puppet would win because it had been dominant before.

Preference and Preference Justification. Children preferred the dominant puppet on $57.3 \%$ trials, which was not significantly different from chance $(p=.098)$. For children, there was no effect of age (months). In contrast, adults chose the dominant puppet significantly less than chance $(31.8 \%, \mathrm{OR}=0.26 ; 95 \% \mathrm{Cl}=.1, .455 ; p=.0001)$, meaning that most preferred the subordinate puppet. Comparison of children and adults found a main effect of age $(\mathrm{OR}=4.62$; $95 \% \mathrm{Cl}=2.35,10.7 ; p<.0001)$, and no main effect of puppet pair or situation type. Thus, children's responses were significantly higher than adults.

As mentioned above, children had one preference justification response while adults had two. Preference justifications were categorized into the following categories:

1. Conflict outcome: referenced the outcome of the conflict, specifically as one agent being more or less aggressive, more or less strong, bullying, winning, losing, being the underdog. For instance, "Because he didn't get the toy last time", "BrownPants keeps taking the toy from him", "I appreciate the underdog", "Because she's a winner", "Because he's stronger."

2. Appearance: mentioned the character's appearance, be it in terms of clothing, features, or overall look. For instance, "She has blonde hair", "She looks nice."

3. Sympathy: reported feeling bad for the subordinate puppet and liking them because of this. For instance, "I feel sorry for her." 
4. Character: stated a trait or disposition that was not immediately tied to the observed conflict, but rather inferred from it. For instance, "He's nice", "He seems easy going." "He may not be as selfish."

5. Other: not answering or giving an explanation that did not fit in any of the above categories. For instance, "I don't know", "Because I like that one so much."

\section{Figure 4}

Preference justification responses from preschoolers and adults in Experiments 1, 2a, 2b, and 3

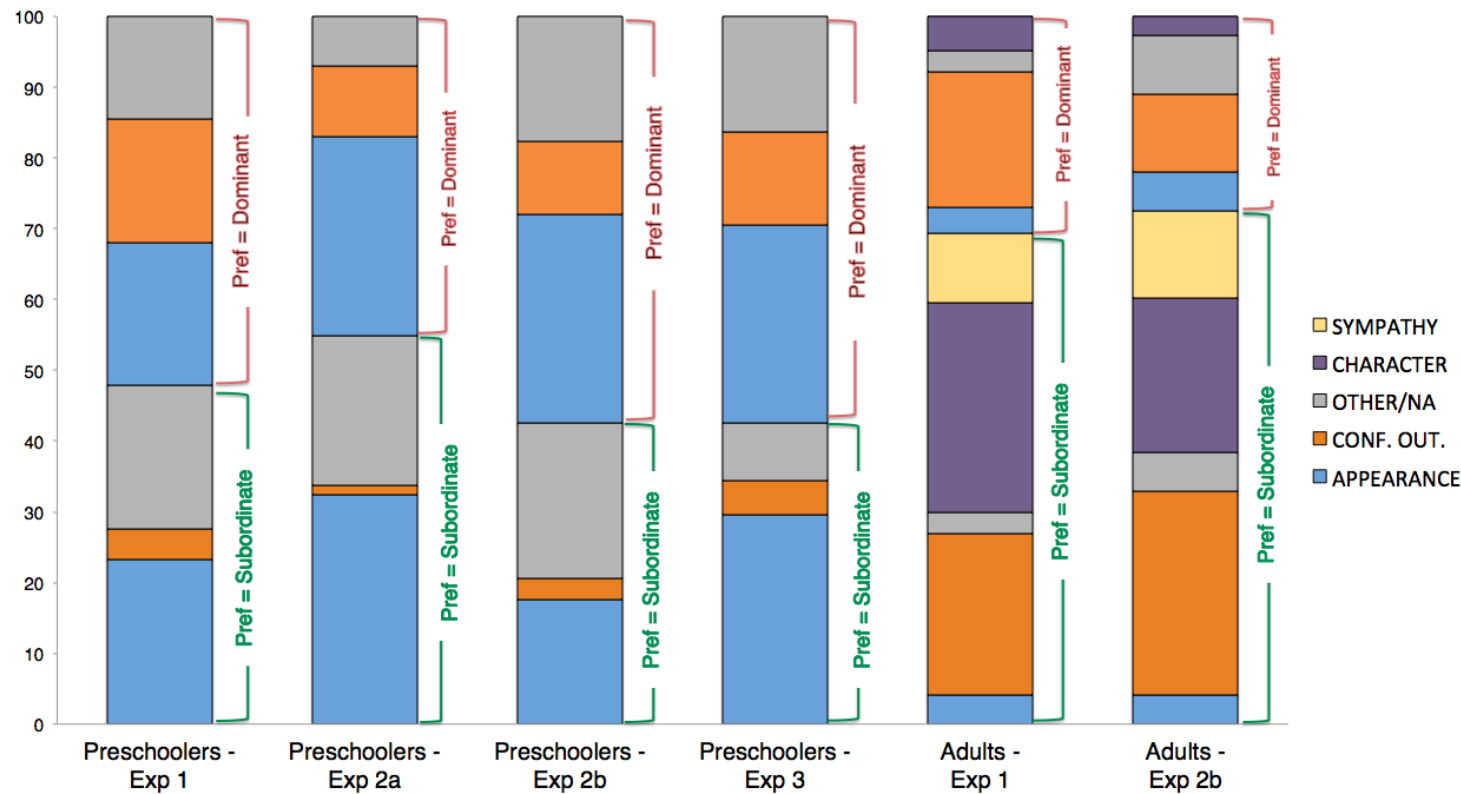

Note. Justifications are broken down by whether the respondents preferred the subordinate or dominant puppet, and color coded by category.

See Figure 4 for a graph of Preference Justifications from all experiments. Given that there were no significant differences between the pattern of justifications in different experiments for preschoolers or adults, responses within each age group were pooled and analyzed together. (Detailed analysis of all preference justifications are given in Supplemental materials.) There were three main findings from preference justifications. First, the majority of preschoolers (84\%) gave superficial (Appearance category) or irrelevant (Other category) 
justifications. Second, preschoolers gave no Character or Sympathy justifications, while adults did, particularly when explaining a preference for the subordinate puppet (55\%). Finally, preschoolers gave fewer Conflict outcome justifications than adults. However, for both children and adults, Conflict outcome justifications were offered more for dominant puppet preference choices than subordinate ones.

\section{Discussion}

In Experiment 1, I asked children to verify the winner of a conflict, and to identify the stronger party in a pair. Children answered both questions correctly as a group, showing that they attended to the scenes, encoded the outcome of a conflict, and used it to identify the dominant individual. Children were equally successful at these questions for the Toy and Bench situations. This success paves the way for the next experiment, in which I use the same animations to ask children about the winners of a conflict in a new situation. At the same time, children were unsystematic in predicting the winner of a new conflict within the same situation. Given that they answered the Outcome question correctly, this failure is not due to misremembering who had won. One possibility is that children thought "Who's going to take the toy?" was meant to indicate who should-rather than would-take the toy. The next experiment changes the procedure in order to make the intent of the question clearer to children. Finally, children did not demonstrate a preference between the dominant and subordinate parties, in line with most past work with preschoolers (e.g. Charafedddine et al., 2016). However, adults preferred the subordinate, a reasonable choice given the harsh dominance displayed by the winning puppet.

\section{Experiment 2a}

The aim of this experiment was to test whether preschoolers generalize dominance roles across situations. Children saw a situation in which one party was clearly dominant, then answered about the outcome of a conflict between the same characters in another situation. For 
instance, a participant saw BlackPants win the toy away from BrownPants, and was later asked to identify which of them would win possession of the bench.

Given children's random responses when predicting the winner of the same situation that they had seen resolved (Exp. 1, Prediction-Same situation), the procedure was changed. At the test trial, children saw a curtain come down and occlude the scene right at the start of the puppets' struggle over the resource. They were then asked to identify the winner of a conflict as if it had ended already (e.g. "Who took the toy?"). To test whether this change in procedure made a difference, the Prediction-Same situation question was included here. Following this, children saw an incomplete conflict in the new situation and predicted who had won there.

\section{Method}

Participants. Seventy-two preschoolers (3-year-olds: $n=24, M=41.7$ months, 12 female; 4-year-olds: $\mathrm{n}=24, M=54.4$ months, 12 female; 5 -year-olds: $\mathrm{n}=24, M=65.4$ months, 12 female) participated. Most children $(n=45)$ came from the same lab-based participant pool as before. The remainder $(n=27)$ were tested at $\left[\_\right]$Museum.

Procedure. Unlike Experiment 1, in which each participant completed two blocks with two different pairs of puppets, children watched one pair of puppets in both situations here. The puppet pair that each child saw was gender-matched to them. Sample stimuli available at https://osf.io/tcuxn/?view_only=8dbd67d74be74970b86ddfa1679f0b80

Introduction. This phase was identical to before, except that a red curtain rose at the start to reveal a picture of the two puppets.

Entrance and Conflict (First situation). These phases were the same as before, with the exception that each character entered twice instead of three times. Like before, the experimenter probed memory of character names before the conflict scene played three times. Whether children saw the Bench situation or Toy situation as their first situation was counterbalanced across participants.

Test. The experimenter asked six test questions. 
1. Prediction-Same situation. A new bout of the conflict in the first situation started playing. However, the red curtain descended right before the start of the struggle over the resource. Next, participants saw the picture that had been used at the start to introduce the puppets, meaning that they were standing apart and the resource was absent. The experimenter asked the child to identify the winner of the conflict, e.g. "Oh, the curtain came down and we didn't get to see who took the toy. Who took the toy?"

2. Prediction-New situation. Next, the other situation that had not been shown so far was presented. If the Toy situation had been shown first, the Bench situation followed next, and vice versa. The curtain appeared again, and rose to show one of the puppets making an entrance in the new situation. After the second puppet's entrance, the start of the conflict over the new resource was shown. As in the previous prediction, the curtain came down right before the start of the struggle. The experimenter then showed a picture of both puppets and asked the child to predict the winner in the new situation, e.g. "They both wanted to sit on the bench, but only one person can sit on the bench. Then the curtain came down and we didn't get to see. Who sat on the bench?"

The remaining test questions (3. Strength; 4. Preference; 5. Prediction-New situation justification; 6. Prediction Justification) were identical to Experiment 1.

\section{Results}

Memory questions. Children remembered the names of the puppets they viewed with high accuracy $(91.7 \%$ correct, $p<.0001$, binomial test, Cohen's $h=.99)$. There were no differences in memory based on gender or age.

Test questions. Figure 5 shows responses to test questions. Results are provided separately below.

1. Prediction-Same situation. Children predicted the winner of the same situation conflict with higher than chance accuracy $(76.4 \%, p<.0001$, binomial test, Cohen's $h=.56)$. There was no effect of age (months), first situation (Toy vs. Bench), or gender. This means that 
children inferred that the dominant puppet would win the resource they had seen him or her win before in a new conflict in the current experiment. A comparison of Prediction-Same situation responses from Experiment 1 and Experiment 2a found a significant difference between the two $\left(X^{2}(1, N=216)=8.89, p=.003\right)$, indicating that the change in procedure made a significant difference to children's responses. Further, as there was no gender effect here, the effect found in Experiment 1 was likely not robust.

\section{Figure 5}

Responses to test questions in Experiments $2 a$ and $2 b$.

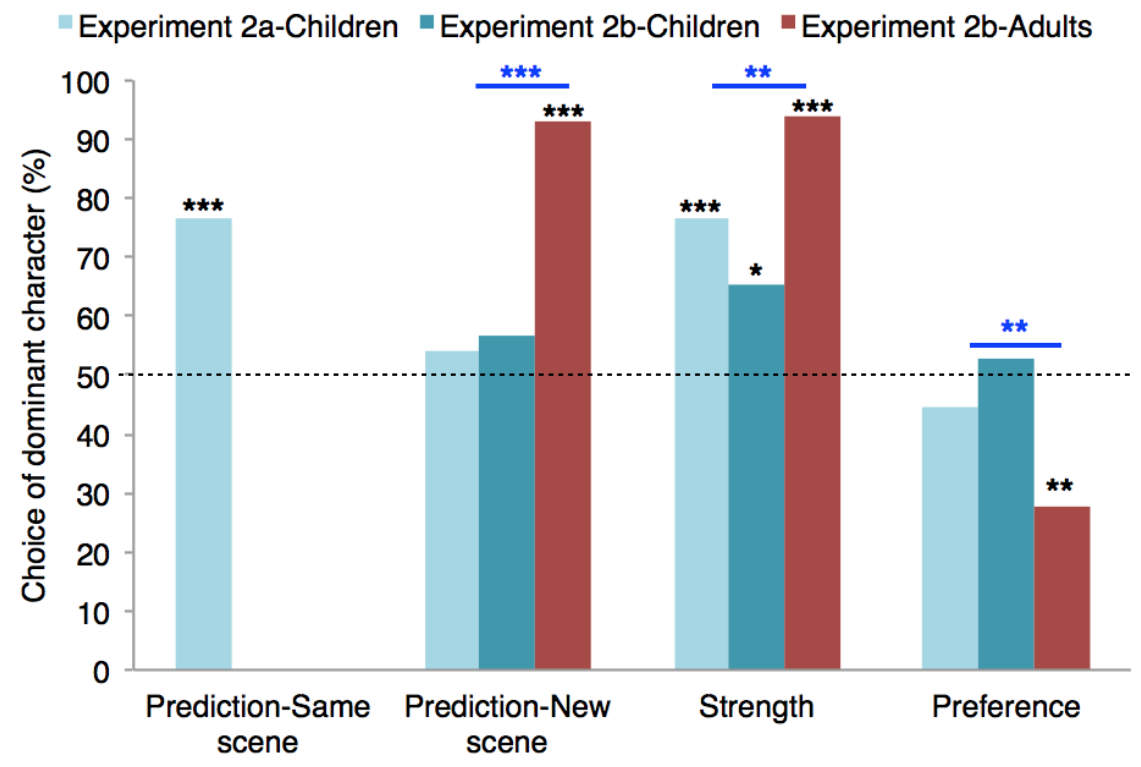

Note. Comparisons against chance (black) and across ages (blue) are noted $\left({ }^{*} p<.05,{ }^{* *} p<\right.$ $\left.0.01,{ }^{* * *} p<0.001\right)$. Dotted line shows chance level. There are no error bars as each participant gave only one response.

2. Prediction-New situation and Prediction Justification. When predicting the winner in the new situation, performance was at chance $(54.2 \%, p=.48$, binomial test). Once again, 
there was no effect of age, first situation, or gender. Thus, children did not generalize the dominant puppet as the winner in the new situation.

As in Experiment 1, justifications were coded into the categories of Dominance, Fairness, and Other (see Figure 6). The majority of responses were in the Other category $(71 \%$ of all responses), which indicates that most children did not consciously attach their choice to either dominance or fairness. When excluding Other responses from analysis, rates of responses were significantly different between those who chose the subordinate puppet (20\% Dominance, $80 \%$ Fairness) and those who chose the dominant (94\% Dominance, 6\% Fairness) as the winner $\left(X^{2}(1, N=21)=11.42, p=.0007\right.$, Cramer's $\left.V=0.74\right)$. In sum, 1$)$ most children gave an irrelevant explanation for their choice, 2) the children who gave a relevant justification were likely to go with Dominance if they picked the dominant puppet and with Fairness if they picked the subordinate puppet.

\section{Figure 6}

Prediction-New situation Justifications from Experiments $2 a$ and $2 b$

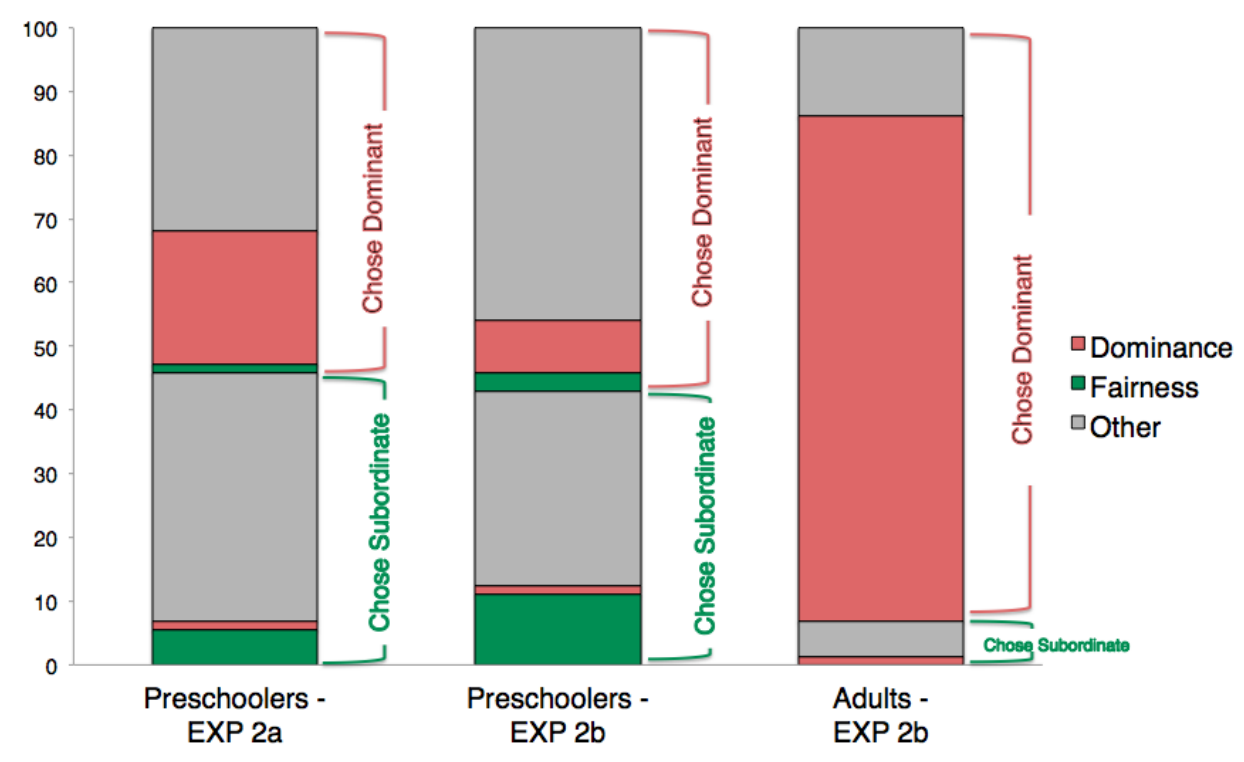

Note. Justifications are broken down by whether the respondents predicted the subordinate or dominant puppet as the winner, and color coded by category. 
3. Strength. Children's responses were significantly better than chance $(76.4 \%$ correct, $p<.0001$, binomial test, Cohen's $h=.56$ ). Like Experiment 1 , there was a main effect of age $(\mathrm{OR}=1.12,95 \% \mathrm{Cl}=1.01,1.13, p=.025)$, but no effect of first situation or gender

4. Preference and Preference Justifications. Children did not have a preference between the dominant and subordinate characters $(45.1 \%$ in favor of dominant, $p=.41)$. There was no effect of age, gender, or first situation on preference responses. Preference Justification responses were coded as before (see Figure 4). See the results section for Experiment 1 for the main findings of preference justifications. See Supplemental materials for detailed analyses.

\section{Discussion}

Children participating in this experiment correctly identified the dominant puppet as the winner in a new bout of conflict in the same situation they had been familiarized with. This indicates that unlike Experiment 1 where children may have interpreted this question as being about who should win, children in Experiment 2 understood that they had to say who had won. Despite this, children did not think the dominant puppet would win in the new situation. One low level possibility with regard to this failure is that some children chose the subordinate so as to switch up their response after they had (correctly) inferred the dominant puppet to be the winner in the same situation. To address this, Experiment $2 \mathrm{~b}$ removes the Prediction-Same situation question so that the Prediction-New situation question is the first test question that children receive. Additionally, given preschoolers' lack of generalization here, the next experiment includes adult participants in order to find out how they would respond.

\section{Experiment 2b}

This experiment is identical to Experiment 2a with the exception that children were not asked to predict the winner in the situation they had seen the dominant puppet win in.

\section{Method}

Participants. A new sample of 72 preschoolers (3-year-olds: $n=24, M=42.2$ months, 12 female; 4-year-olds: $\mathrm{n}=24, M=53.8$ months, 12 female; 5 -year-olds: $\mathrm{n}=24, M=65.6$ 
months, 12 female) participated. The majority participated in the lab $(n=45)$ and the remainder participated in the $\left[\_\right.$Museum $(n=27)$. Additionally, 72 adults participated in the study online $(M=32.4$ years, 33 female, $14 \%$ Asian, 3\% Black or African-American, $74 \%$ White, $6 \%$ mixed, and $4 \%$ other). All were recruited through Prolific and completed the task on Qualtrics.

Procedure. The procedure was identical to Experiment 2a with the exception that the Prediction-Same situation question was not asked.

\section{Results}

Memory questions. Children's memory for puppet names was excellent $(97.2 \%$ correct, $p<.0001$, binomial test, Cohen's $h=1.23$ ), with no effect of age or gender. All but one of the adults remembered puppet names $(98.6 \%, p<.0001$, binomial test, Cohen's $h=1.33)$.

Test questions. Results for test questions are provided below.

1. Prediction-New situation and Prediction Justification. Children did not choose the dominant puppet significantly more than chance $(57 \%, p=.29$, binomial test $)$, but adults did $(93 \%, p<.0001$, binomial test, Cohen's $h=1.04)$. Among children in this experiment, there was no effect of age (months), gender, or first situation. Given the similarity of Experiments $2 a$ and $2 b$, responses were pooled and analyzed together. There was no difference between children's performance in Experiment $2 \mathrm{a}$ and $2 \mathrm{~b}(p=.68)$, nor was there any effect of age in their pooled responses $(p=.4)$. Further, children's responses in the two experiments were not different from chance overall $(55.6 \%, p=.2$, binomial test). In the current experiment, children's and adults' responses were significantly different from each other $(\mathrm{OR}=.10,95 \% \mathrm{Cl}=0.03,0.25, p<$ .0001). Additionally, adults' responses were significantly different from those of children in Experiments $2 \mathrm{a}$ and $2 \mathrm{~b}$ combined $(p<.0001)$. Thus, Experiment $2 \mathrm{~b}$ replicated Experiment $2 \mathrm{a}$. Preschoolers did not generalize the dominant puppet to win in a new situation, but adults did.

Prediction justifications were coded using the same coding system as before, and are provided in Figure 6. Similar to Experiment 2a, the majority of justifications fit in the Other category ( $76 \%$ of all responses). Laying aside 'Other' responses, the rates of justifications were 
significantly different between those who chose the dominant (75\% Dominant justification, $25 \%$ Fairness) and those who chose the subordinate (11\% Dominance justifications, $89 \%$ Fairness) in their prediction response $\left(X^{2}(1, N=17)=7.14, p=.008\right.$, Cramer's $\left.V=0.65\right)$. So, once again, children who chose the dominant puppet were likely to give Dominance explanations and those who thought the subordinate were likely to give Fairness reasons.

Among adults, no one provided Fairness responses, and only 5 out of 72 chose the subordinate puppet as the winner of the new situation. The majority of explanations for those who chose the dominant puppet fit the Dominance category (85\%). In other words, most adults generalized the dominant puppet as the winner of the new situation and most of those explained their choice through dominance.

2. Strength. Both children and adults chose the dominant puppet significantly more often than chance (children: $65.3 \%, p=.013$, binomial test, Cohen's $h=.31$; adults: $94.4 \%, p<$ .0001 , binomial test, Cohen's $h=1.09)$. Among children alone, there was no effect of age (months), gender, or first situation. Considering pooled child responses from Experiments 2a and $2 b$, there was no effect of experiment $(p=.15)$ or gender, but there was a significant effect of child age $(\mathrm{OR}=1.05,95 \% \mathrm{Cl}=1.01,1.09, p=.01)$, indicating a modest improvement in responses with age. A binary logistic regression found a main effect of age group $(O R=.11$, $95 \% \mathrm{Cl}=0.03,0.31, p=.0001)$, indicating that children's responses were lower than those of adults. There was a similar effect of age group when considering data from Experiments $2 a$ and $2 \mathrm{~b}(p=.0001)$, meaning that adults' responses were higher than children's in both experiments.

3. Preference and Preference Justification. As before, children did not have a preference between the dominant and non-dominant characters $(53.5 \%$, binomial test, $p=.63)$. There was no effect of gender or first situation (Toy, Bench) on preferences, but there was a significant, but small, effect of age $(\mathrm{OR}=1.05 ; 95 \% \mathrm{Cl}=1.001,1.10 ; p=.048)$. This indicated that older children were more likely than younger ones to prefer the dominant puppet. In contrast, adults chose the dominante puppet significantly less than chance $(28.2 \%, p=.0002$, 
binomial test, Cohen's $h=0.45)$. Further, there was a significant difference between children and adults in their preference responses $(\mathrm{OR}=2.99,95 \% \mathrm{Cl}=1.51,6.09, p=.002)$. There was also an effect of age group between adults in Experiment $2 \mathrm{~b}$ and children in Experiments 2a and $2 \mathrm{~b}(p=.002)$. In children's pooled responses, there was no effect of experiment $(p=.35)$, age, or gender. See Figure 4 for Preference Justification responses, the results section in Experiment 1 for the main findings from preference justifications, and the Supplemental materials for detailed analyses.

\section{Discussion}

Findings from Experiments $2 a$ and $2 b$ converge. In both samples, children identified the dominant puppet as the stronger character, but did not judge that character to be the winner of the conflict in the second situation. Their justifications suggested that some children consciously chose the subordinate puppet as the winner because they were concerned with turn-taking and fairness. It should be noted that children understood that they were indicating who had won, not who would win. Thus, it seems that many children thought fairness prevailed, meaning that if one party had won the first resource, the other party was bound to have won the second resource. Adults, in contrast, generalized dominance from the first situation to the new one and explained their choice in terms of dominance. The next experiment actively guides children's attention to fairness and dominance before asking for generalization inferences.

\section{Experiment 3}

Children's justifications from previous experiments made clear that both dominance and fairness factored into the inference of who had won a conflict in a new situation. The goal of the current experiment was to test whether priming these concepts, i.e. dominance and fairness, would guide children's inferences in different directions. This priming occurred in the context of a story about three bears who were all eager to read a book out loud. In the Dominance Prime condition, one bear stated that he would read all of the book himself and did so. In the Fairness 
Prime condition, the same bear suggested that they take turns, and each bear read a page. Following this, children saw the same procedure with puppets as Experiment $2 \mathrm{~b}$.

There were a number of possibilities in terms of how considerations of fairness and dominance could affect children's inferences, and I will lay out three of them here. First, priming a concept may invite children to consider it more seriously (compared to previous experiments). If so, children in the Dominance Prime condition should infer that the dominant puppet would win and children in the Fairness Prime should infer that the subordinate puppet would win. Second, priming dominance may lead children to think about the unfairness of the situation (i.e. one bear reading all the book, when all three bears were interested in doing so). As a result, children may be particularly likely to notice that the puppet conflict they witness is also unfair, focus on the unfairness, and think that the subordinate would have won in the new situation. In parallel, priming fairness may lead children to notice how the puppet conflict that follows is different from the peaceful and fair situation with the bears. They may then infer that what is taking place in the puppet conflict is different in nature from situations in which fairness generally prevails, and expect the winner to have won again. If this possibility is true, the Dominance Prime group should choose the subordinate as the winner and the Fairness Prime group should choose the dominant. Third, priming fairness may not make a difference because children's default sensitivity to fairness is saturated. In other words, given the extensive messaging and modeling of fairness that children constantly witness, yet another instance of modeling fairness (in the Three Bears story) would not be particularly salient, and so would not register with them as they infer who had won. On the other hand, by virtue of the high exposure to fairness values, children may be particularly sensitive to instances of unfair behavior such as the dominance conflict between the puppets. If this possibility is true, children in the Fairness Prime condition should respond as children have done in previous experiments (i.e. no systematic inferences), but children in the Dominance Prime condition will focus on fairness and choose the subordinate puppet as the winner. 


\section{Method}

Participants. Sixty-four children aged four and five years $(M=60.5$ months, 31 female $)$ participated in this experiment. All children were recruited from the family participant pool at the

]. Based on race identification available from $39 \%$ of the participant pool, the demographics of the children are $86 \%$ White, $1 \%$ Black, $2 \%$ Asian, and $11 \%$ mixed-race or other. Thirty-six participated in the lab. After the university's closure due to COVID-19 in March 2020, the remaining 28 children participated online. One additional participant was excluded from the final sample due to technical failure.

Materials. The puppet videos used here were the same as the previous experiments. A short story and some accompanying pictures was developed for the priming manipulation. For children participating online, an experimenter videoconferenced with the family through Zoom, and greeted the child and parent before beginning the study. During the experiment itself, the experimenter's camera was off and children could only hear her voice. The stimuli was presented on slides.com, an online presentation platform.

Procedure. This experiment had two phases.

Story phase. In this phase, the experimenter read a story about three bears who were in conflict because they all wanted to be the one to read a book out loud. In the Dominance Prime condition, the situation was resolved by one bear saying that he would read the whole book himself. In the Fairness Prime condition, the same bear suggested that each bear read one page out of the book. Memory questions were asked at the end of the story to test whether children remembered the outcome, "Who got to read the book? Did anyone else get to read the book?" In cases of wrong answers, the resolution of the story was repeated to children. Half the sample received the Dominance Prime and the other half received the Fairness Prime.

Puppetshow phase. This part of the procedure was identical to Experiment $2 \mathrm{~b}$ and thus also very similar to Experiment 2a. Counterbalancing was identical to Experiments $2 \mathrm{a}$ and $2 \mathrm{~b}$.

\section{Results}


Memory questions. Most children answered the memory questions regarding the three bears story correctly $(70.3 \%, p=.002$, binomial test, Cohen's $h=0.42)$. While this number is not at ceiling, it is important to note that children who answered the question incorrectly heard part of the story one more time, giving them another chance to learn the information. Further, memory for puppet names was $94 \%$ accurate $(p<.0001$, binomial test, Cohen's $h=1.07)$.

Test questions. Results for test questions are provided below.

1. Prediction and Prediction Justification. A binary logistic regression found a significant effect of condition $(\mathrm{OR}=2.91,95 \% \mathrm{Cl}=1.05,8.48, p=.043)$, but no effect of testing location (in-lab vs. online) or gender. Comparing responses from each condition to chance showed that children in the Dominance Prime condition were marginally less likely than chance to choose the dominant puppet $(31 \%, p=.0501$, binomial test, Cohen's $h=0.39)$. In contrast, children in the Fairness Prime condition were at chance in their choice between the two puppets (56.2\%, $p=.6$, binomial test). Thus, children in the two conditions responded differently from each other: the Dominance Prime group tended to think the subordinate had won in the new situation while the Fairness Prime group did not make a systematic inference.

Similar to previous experiments, over $60 \%$ of justifications in both conditions fit in the Other category, meaning that they were unrelated to dominance or fairness. Leaving these aside, $100 \%$ of remaining justifications were in line with the child had chosen, meaning that all the children who chose the subordinate puppet gave Fairness explanations and those who chose the dominant puppet gave Dominance explanations. All of this indicates that for children who showed explicit awareness of a reason relevant to the events they had witnessed, responses matched reasoning perfectly.

2. Strength. Children chose the dominant puppet as the stronger party $(65.5 \%$, binomial test, $p=.017$, Cohen's $h=0.32$ ). There were no effects of condition, location, or gender.

3. Preference and Preference Justification. Children did not have a preference between the two characters $(56.2 \%$, binomial test, $p=.38)$, and there were no effects of 
condition, age, location, or gender. Preference justifications can be seen in Figure 4. Main findings from preference are provided in the results for Experiment 1. For detailed analyses of the justifications, see the Supplemental materials.

\section{Discussion}

Priming the concepts of dominance and fairness led to different choices for preschoolers who were tasked with identifying the winner in a new situation. While the fairness prime did not change responses from the baseline observed in previous experiments, children primed with dominance tended to choose the subordinate puppet. This is the first instance of preschoolers deviating from chance performance on the generalization question. Given this pattern of results, the third possibility laid out above is supported: Preschoolers appear to be particularly sensitive to instances of unfair outcomes and they view dominance as unfair behavior. Thus, when primed with dominance, they inferred that the subordinate from the first situation would have prevailed in the next. In contrast, priming children with fairness did not change their behavior from no prime (Exps. 2a, 2b) perhaps because they already expected fairness to prevail in the story with the three bears, and thus listening to it made no change to their inferential process.

\section{General Discussion}

The goal of the current study was to examine whether preschoolers generalize dominant-subordinate roles from one situation to another, as infants have been reported to do (Mascaro \& Csibra, 2012). To test this, I established a dominance relationship between two puppets by showing one win a resource conflict several times, and asked preschoolers to infer the winner of a different type of resource. Even though preschoolers recognized who was dominant in the first situation (Exps. 1-3), they did not generalize dominance from one situation to the next as a group (Exps. 2a, 2b). Children's explanations reveal that some chose the dominant puppet as the winner because he or she had been dominant in the past, some chose the subordinate out of concerns about fairness, and many did not seem aware of the reason for their choice. Further, preschoolers did not generalize roles when they were primed with the 
concepts of dominance or fairness (Exp. 3). In fact, priming dominance pushed children in the opposite direction-they were marginally better than chance in choosing the subordinate puppet as the winner of the new situation. Finally, there were no age differences, and neither the youngest nor the oldest children succeeded. Thus, preschoolers did not generalize dominance in contrast to both infants (Mascaro \& Csibra, 2012) and adults (Exp. 2b).

Why did preschoolers not generalize dominance? Children's justifications showed that at least some of them were basing their inference on fairness considerations, particularly when they chose the subordinate as the winner. This applied both when making an inference about the same situation as before (Exp. 1), as well as when doing so about the new situation (Exps. $2 a, 2 b$, and 3). Further evidence for the role of fairness comes from priming manipulations in Experiment 3. That priming dominance led children to choose the subordinate, while priming fairness did not change children's choices compared to previous experiments suggests two things. First, children saw the dominance prime as an instance of unfairness, and were highly sensitive to unfairness, so they chose the subordinate agent as the winner. Second, the ineffectiveness of the fairness prime indicates that fairness was already expected and top of mind for children. In other words, children seemed to be unphased by demonstrations of fairness but hypersensitive to lack of fairness. This skewed sensitivity makes sense when considering the social world of young children, at least in the cultural context of middle-class American families that our sample came from. Preschoolers are raised with cultural norms that model, encourage, and enforce fair behavior, especially in the forms of sharing, turn-taking, and resource equality in peer settings. In turn, even three-year-olds notice unfair distributions (LoBue et al., 2010), and young children care about equal distribution of resources (Rochat et al., 2009; McAuliffe et al., 2015; Benenson et al., 2007; Gummerum et al., 2010). In light of this, it is not surprising that seeing an instance of fairness in action in the form of the fairness prime in the three bears story did not change their behavior. Taken together, it seems that preschoolers did not generalize dominance as a group because a subset of children were 
considering fairness to begin with when drawing inferences about the winner of a new situation. The dominance prime grew this subset of children further, thus shifting the balance such that most children chose the subordinate as the winner.

As suggested above, preschoolers are sensitive to unfair distributions and outcomes. However, it is unclear why such concerns would manifest in inferences about past outcomes on which children have no control, as was the case with the puppet conflicts. One possibility is that children misunderstood the task. That is, they answered the question of who should win rather than who did win when asked to identify the winner. This was in fact a problem in Experiment 1, where children were at chance when asked to identify the winner in the same situation that they had seen the resolution to before. To remedy this, a procedural change was introduced in Experiment 2a; a curtain fell over the scene during the struggle, and children were explicitly made aware that the conflict had already ended and they had to say who had won. Following this, children chose the dominant puppet significantly more often than chance, and were significantly better than children in Experiment 1. Given this improvement in performance, there is reason to trust that children understood the question about the winner of the new conflict correctly and did not think the dominant puppet would be the winner in the new situation (Exp. $2 a, 2 b, 3)$. Another possibility is that the specific features of the struggle between the two puppets made it seem like neither was fully dominant over the other. Dominance hierarchies exist in many species and within established hierarchies subordinates typically avoid entering conflicts in order to save themselves from probable injury (Bernstein, 1981). If children have some notion of this as observers, the mere occurrence of a physical struggle could suggest to them that the puppets were of relatively comparable rank, and thus it would be fair-and more importantly, highly possible-for the one who had lost to win. While this may be somewhat true, it does not explain the findings. Preschoolers consistently picked the dominant puppet as the stronger one, suggesting that they did not view the puppets as equal in formidability. Further, adults viewing the same stimuli as preschoolers expected the dominant puppet to remain 
dominant across situations. Thus, it is unlikely that viewing struggles precluded children from generalizing dominance. The third and most likely account is that preschoolers conflated probable outcomes with moral ones, a distinction that young children struggle with. Shtulman and Phillips (2017) found that children under the age of six gave comparable responses to whether impossible, improbable, and immoral events were possible, and also comparable responses about whether the same events were permissible. It appears that preschoolers in the current study made similar errors when inferring the winner. In other words, the children who chose the subordinate puppet as the winner may have been particularly sensitive or attentive to the first interaction being morally wrong, and thus they may have found it impossible or improbable for the dominant puppet to win again. As a result, they thought the subordinate had won in the new situation.

Given that children as a group considered fairness as well as dominance when inferring the winner in a new situation, several results need further explanation. First, why did fairness considerations not affect preschoolers' judgments about who had won a new bout of conflict in the same situation as before in Experiment $2 a$ ( $75 \%$ choice of dominant) as it did for inferring the winner of the new situation ( $54 \%$ choice of dominant)? Perhaps seeing the first situation resolve in favor of the dominant agent three times led children to assume that there was no uncertainty in how a new bout of the same conflict would end. Put differently, children had already viewed very strong evidence in favor of one puppet being dominant in the current situation. In contrast, there was no direct evidence for either puppet being dominant in the new situation, so choosing either the dominant or the subordinate agent as the winner were viable options, and a child's inference was guided by whether they focused on dominance or fairness. Second, why did fairness not affect infants' expectations in Mascaro and Csibra's (2012) study? It seems that this was not for lack of fairness expectations as infants, like preschoolers, expect fair distribution of resources (Enright et al., 2017; Dawkins et al., 2019; Sloane et al., 2012). However, even if we take these findings as evidence that infants have an intuitive moral sense, 
that does not mean that moral considerations easily interfere with other social inferences. In fact, infants' construals of the scenes may have been limited to the concept that was being explicitly highlighted, i.e. dominance. Preschoolers' richer conceptual repertoires, in contrast, likely led them to consider and arrive at more construals. This difference-having access to fewer vs. more numerous construals and interpretations of events-may in fact be one contributing factor to divergence between infancy and preschooler findings (Afshordi \& Carey, under review). Thus, infants may have failed to see the moral relevance of the scenes, or failed to consider the moral angle because dominance was salient. Third, why did fairness not affect adults' inferences? It is likely that adults, like preschoolers, believed that winning the resource by force was not moral. However, adults seemed to find the inference about the winner straightforward, thinking that more formidable agents get access to more resources. Finally, why did preschoolers factor fairness into their inferences here, even though they allocate more resources to dominant agents (Charafeddine et al., 2016) and expect dominant agents to have more resources (Charafeddine et al., 2015)? Perhaps the relatively harsh struggle between the puppets cued children to the unfairness of one agent losing out to the other in a way that simply knowing the outcome without having watched it would not have. Related to this idea, infants are surprised to see a person divide resources unequally between two agents, but not surprised if they see an existing unequal resource distribution revealed (Meristo et al., 2016). Thus, the specific way in which the dominance relationship was established may have led to different patterns of findings.

The main goal in Mascaro and Csibra's (2012) study was to investigate the format of infants' dominance concepts. Their experiments found evidence of a relational concept rather than an individual one, meaning that infants attributed dominance ranks to agents in a pair, but not to individual agents independently. I found no evidence of such relational format in preschoolers' concepts of dominance here. However, there is no reason to think that this absence of evidence is evidence of absence. But what about the content of the representation? 
Mascaro and Csibra (2012) situate possibilities for infants' representational content within the framework of infants' agency and action understanding, e.g. "A prevails over B." In the end, they consider infants' content to be social in a lean sense. The findings from the current paper paint a different picture for preschoolers' representation. For preschoolers, at least in the mostly White, American middle-class context, the representation is richly social. Preschoolers appear to understand the harsh and coercive type of dominance shown here to be tied to strength, unfair in nature, equally open to stability and change across different situations, and irrelevant to preference. Future work should compare this to their concept of dominance when it is portrayed differently (e.g. the dominant agent threatens force but does not deploy it and the subordinate defers), and to their concept of prestige.

With regard to a preference, no experiment found evidence of preschoolers liking one agent over the other, while adults preferred the subordinate in two separate experiments. Strikingly, children's preference justifications show that they failed to link their choice to the events they had witnessed. Instead, they gave mostly superficial and irrelevant reasons, especially when explaining why they liked the subordinate. The majority of adults who preferred the subordinate mentioned sympathy or general inferences they had made about the character of the puppets. It is possible that such reasons drove children's preference for the subordinate too but they were unable to articulate them. Alternatively, the absence of character inferences from children may indicate that they did not view the puppets as positive or negative overall in the same way that many adults seem to have done. This would imply that although many children viewed the dominance conflict as morally unfair, they did not ascribe stable traits to the individuals based on it.

The current study was limited in a number of ways. First, the sample was homogeneous, both in terms of race and socioeconomic status. The population of children I had access to when collecting data were predominantly White and came from middle to upper class families. It is not clear whether children from racial minority groups or low socioeconomic backgrounds 
would draw the same inferences as those reported here. In fact, it is possible that those children would be more aware of the harsh reality of widespread systemic inequalities and therefore expect existing power dynamics to be less susceptible to change in any given situation, including the resource conflicts presented here. They may view one agent's forceful prevalence over another as morally wrong, but still see it as strong evidence for the same agent's prevalence in other situations. Second, the situations that children viewed were intentionally limited to two. As a result, while the findings suggest a lack of generalization for other types of situations too, they do not provide direct evidence on whether preschoolers generalize dominance from a resource conflict like the one presented here to an all together different type of dominance conflict. For instance, who do children think would win the argument about what dessert the puppets can eat, or what game they play together if one of them has won a resource conflict in the past? Future work should explore this question, as well as investigating the amount of evidence preschoolers need in order to expect a dominant agent to be dominant again. It is possible that offering three or more situations in which one party is dominant would turn the tide. 


\section{References}

Afshordi \& Carey (under review). Preschoolers' recognition of and inferences from observed imitation. Preprint available at https://psyarxiv.com/zmsx3/

Benenson, J. F., Pascoe, J., \& Radmore, N. (2007). Children's altruistic behavior in the dictator game. Evolution and Human Behavior, 28(3), 168-175. https://doi.org/10.1016/j.evolhumbehav.2006.10.003

Bernstein, I. S. (1981). Dominance: The baby and the bathwater. Behavioral and Brain Sciences, 4(3), 419-429. https://doi.org/10.1017/S0140525X00009614

Brey, E., \& Shutts, K. (2015). Children use nonverbal cues to make inferences about social power. Child Development, 86(1), 276-286. https://doi.org/10.1111/cdev.12334

Castelain, T., Bernard, S., Van der Henst, J. B., \& Mercier, H. (2015). The influence of power and reason on young Maya children's endorsement of testimony. Developmental Science, 19(6), 957-966. https://doi.org/10.1111/desc.12336

Charafeddine, R., Billamboz, C., Noveck, I., \& Van der Henst, J-B. (2018). Preschoolers' social preferences in a social dominance context. In P. Saint-Germier (Ed.) Language, Evolution and Mind. Essays in honour of Anne Reboul. College Publications. pp. 247262.

Charafeddine, R., Mercier, H., Clément, F., Kaufmann, L., Berchtold, A., Reboul, A., \& Van der Henst, J. B. (2015). How preschoolers use cues of dominance to make sense of their social environment. Journal of Cognition and Development, 16(4), 587-607. https://doi.org/10.1080/15248372.2014.926269

Charafeddine, R., Mercier, H., Clément, F., Kaufmann, L., Reboul, A., \& Van der Henst, J.-B. (2016). Children's allocation of resources in social dominance situations. Developmental Psychology, 52(11), 1843-1857. https://doi.org/10.1037/dev0000164

Charafeddine, R., Zambrana, I. M., Triniol, B., Mercier, H., Clément, F., Kaufmann, L., ... \& Van der Henst, J. B. (2020). How Preschoolers Associate Power with Gender in Male- 
Female Interactions: A Cross-Cultural Investigation. Sex Roles, 1-21. https://doi.org/10.1007/s11199-019-01116-x

Charlesworth, W. R., \& La Freniere, P. (1983). Dominance, friendship, and resource utilization in preschool children's groups. Ethology and Sociobiology, 4(3), 175-186. https://doi.org/10.1016/0162-3095(83)90028-6

Cheng, J. T., \& Tracy, J. L. (2014). Toward a unified science of hierarchy: Dominance and prestige are two fundamental pathways to human social rank. In The psychology of social status (pp. 3-27). Springer, New York, NY.

Chudek, M., Heller, S., Birch, S., \& Henrich, J. (2012). Prestige-biased cultural learning: Bystander's differential attention to potential models influences children's learning. Evolution and Human Behavior, 33(1), 46-56. https://doi.org/10.1016/j.evolhumbehav.2011.05.005

Cogsdill, E. J., Todorov, A. T., Spelke, E. S., \& Banaji, M. R. (2014). Inferring character from faces: A developmental study. Psychological Science, 25(5), 1132-1139. https://doi.org/10.1177/0956797614523297

Dawkins, M., Sloane, S., \& Baillargeon, R. (2019). Do infants in the first year of life expect equal resource allocations? Frontiers in Psychology, 10, 116 https://doi.org/10.3389/fpsyg.2019.00116

Enright, E. A., Alonso, D. J., Lee, B. M., \& Olson, K. R. (2020). Children's Understanding and Use of Four Dimensions of Social Status. Journal of Cognition and Development, 21(4), 573-602. https://doi.org/10.1080/15248372.2020.1797745

Enright, E. A., Gweon, H., \& Sommerville, J. A. (2017). 'To the victor go the spoils': Infants expect resources to align with dominance structures. Cognition, 164, 8-21. https://doi.org/10.1016/j.cognition.2017.03.008 
Fiske, A. P. (1992). The four elementary forms of sociality: framework for a unified theory of social relations. Psychological Review, 99(4), 689. https://doi.org/10.1037/0033295X.99.4.689

Gazes, R. P., Hampton, R. R., \& Lourenco, S. F. (2017). Transitive inference of social dominance by human infants. Developmental Science, 20(2), e12367. https://doi.org/10.1111/desc.12367

Gummerum, M., Hanoch, Y., Keller, M., Parsons, K., \& Hummel, A. (2010). Preschoolers' allocations in the dictator game: The role of moral emotions. Journal of Economic Psychology, 31(1), 25-34. https://doi.org/10.1016/j.joep.2009.09.002

Hawley, P. H. (1999). The ontogenesis of social dominance: A strategy-based evolutionary perspective. Developmental Review, 19(1), 97-132. https://doi.org/10.1006/drev.1998.0470

Hawley, P. H. (2002). Social dominance and prosocial and coercive strategies of resource control in preschoolers. International Journal of Behavioral Development, 26(2), 167176. https://doi.org/10.1080/01650250042000726.

Hawley, P. H. (2003). Strategies of control, aggression, and morality in preschoolers: An evolutionary perspective. Journal of Experimental Child Psychology, 85(3), 213-235. https://doi.org/10.1016/S0022-0965(03)00073-0.

Henrich, J., \& Gil-White, F. J. (2001). The evolution of prestige: Freely conferred deference as a mechanism for enhancing the benefits of cultural transmission. Evolution and Human Behavior, 22(3), 165-196. https://doi.org/10.1016/S1090-5138(00)00071-4

Hood, B., Carey, S., \& Prasada, S. (2000). Predicting the outcomes of physical events: Twoyear-olds fail to reveal knowledge of solidity and support. Child Development, 71(6), 1540-1554. https://doi.org/10.1111/1467-8624.00247

Gülgöz, S., \& Gelman, S. A. (2017). Who's the boss? Concepts of social power across development. Child Development, 88(3), 946-963. https://doi.org/10.1111/cdev.12643 
Kajanus, A., Afshordi, N., \& Warneken, F. (2020). Children's understanding of dominance and prestige in China and the UK. Evolution and Human Behavior, 41(1), 23-34. https://doi.org/10.1016/j.evolhumbehav.2019.08.002

LoBue, V., Nishida, T., Chiong, C., DeLoache, J. S., \& Haidt, J. (2011). When getting something good is bad: Even three-year-olds react to inequality. Social Development, 20(1), 154170. https://doi.org/10.1111/j.1467-9507.2009.00560.x

Mandalaywala, T. M., Tai, C., \& Rhodes, M. (2020). Children's use of race and gender as cues to social status. PloS One, 15(6), e0234398. https://doi.org/10.1371/journal.pone.0234398

Margoni, F., Baillargeon, R., \& Surian, L. (2018). Infants distinguish between leaders and bullies. Proceedings of the National Academy of Sciences, 115(38), E8835-E8843. https://doi.org/10.1073/pnas.1801677115

Mascaro, O., \& Csibra, G. (2012). Representation of stable social dominance relations by human infants. Proceedings of the National Academy of Sciences, 109(18), 6862-6867. https://doi.org/10.1073/pnas.1113194109

Mascaro, O., \& Csibra, G. (2014). Human infants' learning of social structures: The case of dominance hierarchy. Psychological Science, 25(1), 250-255. https://doi.org/10.1177/0956797613500509

McAuliffe, K., Jordan, J. J., \& Warneken, F. (2015). Costly third-party punishment in young children. Cognition, 134, 1-10. https://doi.org/10.1016/j.cognition.2014.08.013

Meristo, M., Strid, K., \& Surian, L. (2016). Preverbal infants' ability to encode the outcome of distributive actions. Infancy, 21(3), 353-372. https://doi.org/10.1111/infa.12124

Onishi, K. H., \& Baillargeon, R. (2005). Do 15-month-old infants understand false beliefs? Science, 308(5719), 255-258. https://doi.org/10.1126/science.1107621 
Over, H., \& Carpenter, M. (2015). Children infer affiliative and status relations from watching others imitate. Developmental Science, 18(6), 917-925.

\section{https://doi.org/10.1111/desc.12275}

Pellegrini, A. D., Roseth, C. J., Mliner, S., Bohn, C. M., Van Ryzin, M., Vance, N., Cheatham, C.L. \& Tarullo, A. (2007). Social dominance in preschool classrooms. Journal of Comparative Psychology, 121(1), 54. https://doi.org/10.1037/0735-7036.121.1.54

Powell, L. \& Spelke, E. (2018). Human infants' understanding of social imitation: Inferences of affiliation from third party observations. Cognition, 170, 31-48. https://doi.org/10.1016/j.cognition.2017.09.007

Pun, A., Birch, S. A., \& Baron, A. S. (2016). Infants use relative numerical group size to infer social dominance. Proceedings of the National Academy of Sciences, 113(9), 23762381. https://doi.org/10.1073/pnas.1514879113

R Core Team (2017). R: A language and environment for statistical computing. R Foundation for Statistical Computing, Vienna, Austria. URL http://www.R-project.org/

Rochat, P., Dias, M. D., Liping, G., Broesch, T., Passos-Ferreira, C., Winning, A., \& Berg, B. (2009). Fairness in distributive justice by 3-and 5-year-olds across seven cultures. Journal of Cross-Cultural Psychology, 40(3), 416-442. https://doi.org/10.1177/0022022109332844

Russon, A. E., \& Waite, B. E. (1991). Patterns of dominance and imitation in an infant peer group. Ethology and Sociobiology, 12(1), 55-73. https://doi.org/10.1016/01623095(91)90012-F

Shtulman, A., \& Phillips, J. (2018). Differentiating "could" from "should": Developmental changes in modal cognition. Journal of Experimental Child Psychology, 165, 161-182. http://dx.doi.org/10.1016/j.jecp.2017.05.012

Sidanius, J., \& Pratto, F. (2001). Social dominance: An intergroup theory of social hierarchy and oppression. Cambridge University Press. 
Sloane, S., Baillargeon, R., \& Premack, D. (2012). Do infants have a sense of fairness? Psychological Science, 23(2), 196-204. https://doi.org/10.1177/0956797611422072

Spelke, E. S., Breinlinger, K., Macomber, J., \& Jacobson, K. (1992). Origins of knowledge. Psychological Review, 99(4), 605. https://doi.org/10.1037/0033-295X.99.4.605

Stavans, M., \& Diesendruck, G. (2021). Children Hold Leaders Primarily Responsible, Not Entitled. Child Development, 92(1), 308-323. https://doi.org/10.1111/cdev.13420

Terrizzi, B. F., Brey, E., Shutts, K., \& Beier, J. S. (2019). Children's developing judgments about the physical manifestations of power. Developmental Psychology, 55(4), 793. https://doi.org/10.1037/dev0000657

Thomas, A. J., \& Sarnecka, B. W. (2019). Infants choose those who defer in conflicts. Current Biology, 29(13), 2183-2189. https://doi.org/10.1016/j.cub.2019.05.054

Thomas, A. J., Thomsen, L., Lukowski, A. F., Abramyan, M., \& Sarnecka, B. W. (2018). Toddlers prefer those who win but not when they win by force. Nature Human Behaviour, 2(9), 662-669. https://doi.org/10.1038/s41562-018-0415-3

Thomsen, L., Frankenhuis, W. E., Ingold-Smith, M., \& Carey, S. (2011). Big and mighty: Preverbal infants mentally represent social dominance. Science, 331(6016), 477-480. https://doi.org/10.1126/science.1199198

Van Vugt, M., \& Tybur, J. M. (2015). The evolutionary foundations of status hierarchy. In Buss, D. M. (Ed.). The Handbook of Evolutionary Psychology, Foundations (Vol. 1). John Wiley \& Sons.

Wellman, H. M., Cross, D., \& Watson, J. (2001). Meta-analysis of theory-of-mind development: The truth about false belief. Child Development, 72(3), 655-684. https://doi.org/10.1111/1467-8624.00304 


\section{Supplemental material}

Note. This document provides more details of the analyses for Preference Justifications from preschoolers and adults across all experiments.

\section{Preference justifications}

Preschoolers did not have a preference between the dominant and subordinate puppets in any experiment (50.4\% average preference for dominant puppet), while adults in both Experiments 1 and $2 b$ preferred the subordinate puppet (29.7\% average preference for the dominant puppet). Given the convergence of the findings across experiments, justification frequencies from children in different experiments were compared to each other, and the same was done for those from adults.

Preschoolers. Rates of justifications in different categories were compared for children who had chosen the subordinate puppet in Experiments 1, 2a, 2b, and 3. There was no significant difference $\left(X^{2}(6, N=127)=8.31, p=.22\right)$, suggesting that children who liked the subordinate were offering similar numbers of justifications in each category across experiments. The same analysis was conducted on justifications from children who chose the dominant puppet across all experiments. Once again, there was no significant difference between experiments $\left(X^{2}(6, N=142)=5.7, p=.46\right)$. Given the similarity of rates across experiments, justification data from all experiments was pooled together (see Table S-1). In this pooled set, rates of justifications from children who preferred the dominant puppet were significantly different from those who preferred the subordinate puppet $\left(X^{2}(2, \mathrm{~N}=269)=15.45, p=.0004\right.$, Cramer's $V=0.24)$. The proportion of justifications fitting in the Appearance category compared to other categories was similar for children who preferred the subordinate and those who preferred the dominant $\left(54 \%\right.$ vs. $\left.50 \%, X^{2}(1, N=129)=0.50, p=.48\right)$. Thus, the difference between the subsets of children was driven by differences in the two remaining categories $\left(X^{2}(1\right.$ , $N=129)=15.05, p=.0001$, Cramer's $V=0.34$ ): Children who preferred the subordinate gave more Other justifications (39\%) and less Conflict outcome ones (7\%), while children who 
preferred the dominant puppet gave roughly equal Other (26\%) and Conflict outcome justifications (24\%).

Thus, preschoolers' justifications show the following patterns:

1) Almost all (93\%) children who preferred the subordinate puppet and the majority of those who preferred the dominant $(76 \%)$ gave superficial or irrelevant justifications (Appearance or Other categories).

2) Conflict outcome explanations were more common among children who preferred the dominant than those who preferred the subordinate $\left(24 \%\right.$ vs. $7 \%, X^{2}(1, N=269)=14.19, p=$ .0003 , Cramer's $V=0.23$ ).

\section{Table S-1}

Percentage rates of justifications by category for pooled data from preschoolers (Exps. 1, 2a, 2b, 3) and adults (Exps. 1, 2b), separated by whether they preferred the subordinate or dominant puppet

\begin{tabular}{lccccc}
\hline $\begin{array}{c}\text { Age group/Preferred } \\
\text { agent }\end{array}$ & Appearance & $\begin{array}{c}\text { Conflict } \\
\text { outcome }\end{array}$ & Other & Character & Sympathy \\
\hline Preschoolers/Subordinate & 54 & 7 & 39 & 0 & 0 \\
Preschoolers/Dominant & 50 & 24 & 26 & 0 & 0 \\
Adults/Subordinate & 6 & 34 & 5 & 40 & 15 \\
Adults/Dominant & 14 & 58 & 14 & 15 & 0 \\
\hline
\end{tabular}

Adults. Similar to analyses with children, rates of justifications in different categories were compared for adults in different experiments. Across Experiments 1 and $2 b$, there was no 
significant difference between the justification rates for adults who preferred the subordinate puppet $\left(X^{2}(4, \mathrm{~N}=238)=3.24, p=.52\right)$, or for adults who preferred the dominant $\left(X^{2}(3, \mathrm{~N}=\right.$ $102)=7.26, p=.064)$. Therefore, data were pooled together (see Table S-1). In this pooled dataset, the rates of justifications when favoring the dominant puppet were different from when favoring the subordinate (Fisher's exact test, $p<.0001$ ).

The main findings from adults' justifications are:

1) Character and Sympathy justifications were offered more when justifying a preference for the subordinate than for the dominant ( $40 \%$ vs. $15 \%$ for Character, $15 \%$ vs. $0 \%$ for Sympathy, Fisher's exact test, $p=.02$ )

2) Conflict outcome explanations were more commonly offered for preferring the dominant than the subordinate $\left(58 \%\right.$ vs. $34 \%, X^{2}(1, N=340)=16.09, p=.0001$, Cramer's $V=$ $.22)$.

Comparing preschoolers and adults. Data pooled from preschoolers (Exps. 1, 2a, 2b, 3) were compared with those from adults (Exps. 1, 2b). There was a significant difference between children and adults who had preferred the subordinate puppet (Fisher's exact test, $p=$ .0005), as well as between children and adults who had preferred the dominant (Fisher's exact test, $p<.0001)$. The pattern of differences becomes clearer to understand when considering the following:

1) Children gave far more superficial and irrelevant justifications than adults ( $93 \%$ vs. $11 \%$ for those who liked the subordinate; $76 \%$ vs. $28 \%$ for those who liked the dominant).

2) Children gave fewer Conflict outcome justifications than adults ( $7 \%$ vs. $34 \%$ for those who liked the subordinate; $24 \%$ vs. $58 \%$ for those who liked the dominant).

3) Children gave no Character or Sympathy justifications but adults gave a sizable number ( $0 \%$ vs. $55 \%$ for those who preferred the subordinate; $0 \%$ vs. $15 \%$ for those who preferred the dominant). 